\title{
Phytochemicals for Controlling Obesity-Related Cancers
}

ISSN: 2637-773X

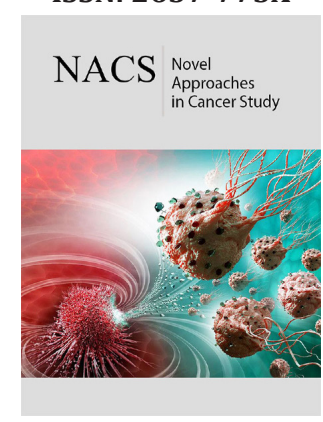

*Corresponding author: Madhumita Roy, Department of Environmental Carcinogenesis and Toxicology, Chittaranjan National Cancer Institute, 37, S. P. Mukherjee Road, Kolkata-700026, India

Submission: 侮 May 29, 2020

Published: 沮June 26, 2020

Volume 4 - Issue 5

How to cite this article: Madhumita Roy, Amitava Datta. Phytochemicals for Controlling Obesity-Related Cancers. Nov Appro in Can Study. 4(5). NACS.000600. 2020. DOI: 10.31031 /NACS.2020.04.000600

Copyright@ Madhumita Roy, This article is distributed under the terms of the Creative Commons Attribution 4.0 International License, which permits unrestricted use and redistribution provided that the original author and source are credited.

\section{Madhumita Roy ${ }^{1 *}$ and Amitava Datta ${ }^{2}$}

${ }^{1}$ Department of Environmental Carcinogenesis and Toxicology, Chittaranjan National Cancer Institute, 37, S. P. Mukherjee Road, Kolkata-700026, India

${ }^{2}$ Department of Computer Science and Software Engineering, University of Western Australia. 35 Stirling Highway, Perth, WA 6009, Australia

\begin{abstract}
Obesity related diseases are on the rise worldwide and obesity is an economic burden on the public health system in most developed and developing countries. The control of obesity is a major challenge that is hard to solve using medication and surgical procedures as those often have serious side effects. Our focus in this article is to highlight the extensive research literature on use of plant-derived chemicals or phytochemicals for control of obesity and obesity related diseases with a particular focus on several types of cancer. We discuss the genes, proteins and pathways involved in obesity and its control, and discuss how current research has revealed the beneficial effects of plant-derived chemicals or phytochemicals on these genes and pathways.
\end{abstract}

Keywords: Obesity; Phytochemicals; Cancer; Adiposity; BMI; Signalling pathways; Genes

\section{Introduction}

Obesity is the state of being overweight, a condition caused due to excessive rate of accumulation and storage of fat in the body. Obesity not only affects appearance, but leads to a number of health issues. The disparity in calorie consumption and calorie burning leads to energy imbalance, which is a lead cause of obesity. Body mass index (BMI) is a measure of obesity or adiposity. BMI is defined as the ratio of the weight and square of the height. The root cause of obesity may be due to uncurbed intake of food, sedentary life style without any physical activity and genetic susceptibility [1]. Endocrine disorders, genes, mental disorder and sometimes medications also contribute to obesity [2]. Many obese people eat very little, yet they are overweight due to slow metabolism [3].

Obesity has become an epidemic worldwide in the modern age and millions of people die every year due to obesity. The prevalence of obesity across the globe has become three times since 1975 [4]. Malnutrition is a known cause of death, but deaths due to being overweight is sometimes more alarming than deaths from being underweight. Overweight individuals are often at a higher risk of developing a plethora of medical problems. Comorbidity is a big problem with obese patients. The upward trend of obesity has a tremendous impact on economy, significant comorbidities and hence diminished lifespan in the population [5]. The associated health complications include type 2 diabetes mellitus (T2DM), insulin resistance, hypertension, cardiovascular disease, stroke, arthritis, gout, dyslipidemia, sleep apnea, gastroesophageal reflux, polycystic ovarian disease (PCD) and infertility [6]. Obesity is often associated with psychiatric problems and behavioral alterations. Mood disorders, personality problems, and sometimes schizophrenia may be caused due to obesity [5]. Obesity is the cause of a number of cancers like breast, endometrial and gallbladder cancer in women and prostate and colorectal cancer in men [7]. Obesity enhances mortality from several cancers like colon, kidney, liver, esophagus, gallbladder, multiple myeloma and non-Hodgkin's lymphoma [8].

\section{Causes of Obesity}

The fat cells once consumed as food, remain for an indefinite period in our body. The size of fat cells can be reduced, but we cannot remove fat cells except for metabolic breaking down of the cells. Therefore, it is important to address the approaches for obesity prevention 
and control that can prevent or reduce accumulation of fat cells in the body. In order to do so, it is important to know the risk factors for obesity. These are excessive intake of energy rich food, junk food with more calorie and less nutrients, very little physical activity, sedentary lifestyle, very little or too much of sleep, genetic factors, family history, racial/ethnic differences, depression or mental stress, intake of certain drugs like steroids etc., lack of understanding of nutrition, poor socio-economic and socio-cultural status to name a few. A number of genetic markers are known, which are responsible for increased susceptibility to obesity [9]. Obesity is responsible for the initiation and progression of many types of cancers. Obesity causes low level of inflammation, which may cause damage to the DNA. Chronic inflammation is a risk factor for many cancers [10]. Chronic inflammation of the gallbladder may be caused by gallstones, which are quite common in obese individuals. Therefore, gallbladder cancer may be one of the cancers caused by obesity [11]. One of the causes of esophageal cancer is Barrett disease or gastroesophageal reflux disease, which may be caused due to inflammation. Another inflammatory condition is chronic ulcerative colitis. Hepatitis is also a liver disease, caused by inflammation and both may cause liver cancer [12]. Fat tissues are deposited due to obesity and as a result an excess amount of estrogen is secreted. Overproduction of estrogen enhances the risk of ovarian, breast and endometrial cancers. Overweight individuals generally have high insulin and insulin like growth factor-1 (IGF1) levels. These conditions increase the risk of colon, endometrial, prostate and kidney cancers [13].

Fat cells in obese people regulate two important proteins, i.e. AMP-activated protein kinase and mammalian target of rapamycin (mTOR). Both are implicated in carcinogenesis. Scaffolding that surrounds breast cells is altered due to obesity [14], also, immune responses are altered, which in turn alter NF- $\kappa \mathrm{B}$ and oxidative stress [15]. Therefore, it is clear that excessive body fat increases the risk for a number of cancers. These cancers include breast, endometrial, esophageal, colorectal, gallbladder, gastric, kidney, liver, multiple myeloma, meningioma, ovarian, pancreatic, thyroid etc. BMI, which gives a good measure of obesity, compared to weight alone, is associated with some of the cancers. High BMI is related to breast, colorectal, ovarian and thyroid cancers.

\section{Genes and Pathways in Obesity Related Cancers}

As mentioned before, obesity has been implicated in several cancers. Metabolic conditions due to obesity quite often result in facilitating tumor growth. We will discuss in this section some of the key metabolic tendencies due to obesity, and how they are related to genes and genetic pathways.

\section{Genes and proteins related to obesity}

One of the common risk factors for Type 2 diabetes mellitus (T2DM) is obesity. Insulin resistance is the primary cause for T2DM, and insulin resistance results in hyperinsulinemia, the state in which an elevated level of insulin circulates in the blood. This is due to the fact that the receptors on the cells become less sensitive to insulin and as a result excess amount of glucose accumulates in the cells. Elevated levels of insulin may further cause growths in tissues, and may also increase the levels of insulin-like growth factor 1 (IGF-1). The elevated levels of IGF-1 interact with cell surface receptors and promote tumor growth. There are two main genetic pathways involved in the tumor promoting growth due to elevated levels of insulin and IGF-1, the PI3K-AKT-mTOR and the Ras-RafMEK-MAPK [16-18]. The literature on use of phytochemicals in cancer prevention and treatment, as well as their effects on the genes and pathways mentioned in this section is vast. We only give some examples here, and refer the reader to the book by Roy and Datta [19] for more details.

Adipose tissue is a loose connective tissue made of adipocytes. The main role of adipose tissue is to store energy in the form of lipids, cushioning and insulation. It is one of the major endocrine organs, producing hormones like estrogen, resistin, leptin, and cytokines like Tumor Necrosis Factor- $\alpha$ (TNF- $\alpha$ ). White adipose tissue (WAT) and brown adipose tissue (BAT) are the two types of adipose tissues present in humans and other mammals [20]. They have different colors, functions, different cellular compositions and localization. WAT is the major part of body's adipose tissue and constitutes most of the total body fat and is also the source of free fatty acids (FFA). Its excessive accumulation might lead to obesity and obesity-related diseases. Most common is "android obesity" the excess WAT in the upper parts of body. This kind of obesity represents a strong risk factor for several inflammatory pathologies. "Gynoid obesity" is the excess WAT in other lower body parts and usually does not have much metabolic complications [20,21]. BAT on the other hand is mainly for adaptation due to cold, generates energy or heat from nonoxidative phosphorylation [22]. Fat cells in BAT are smaller in number, and have richer vascular supplies. They also have more abundant mitochondrial chromogens, responsible for the brown color. Positron emission tomography demonstrates that in adult humans metabolically active BAT are found in axillary, cervical, paraventral and supraclavicular regions, which are induced in response to cold [23]. BAT is a potential target for both gene expression manipulation and pharmacological intervention for combating human obesity $[24,25]$.

Adipose tissue is the source of soluble molecules (adipokines), secreted by adipocytes. Adipokines like Leptin, Adiponectin, Interleukin-6 (IL-6), TNF- $\alpha$ etc are linked to inflammation and there is a hypothesis that elevated inflammatory adipokines contribute to carcinogenesis. Precise ratio between Adiponectin to Leptin is crucial in cancer. TNF- $\alpha$ is secreted by adipocytes and was the first identified inflammatory cytokine. TNF- $\alpha$ expression in white adipose tissue (WAT) was first shown in rodents, and was significantly increased in obese models [26]. TNF- $\alpha$ may play a role in the development of insulin resistance in several ways, including the inhibition of insulin receptor signaling pathway $[27,28]$. It is not clearly understood to which extent TNF- $\alpha$ produced in adipose tissue goes into circulation, although it is known that there is a correlation between the TNF- $\alpha$ system (including the soluble receptors) and indices of obesity [29]. It is known that TNF- $\alpha$ is an important regulator for the synthesis of IL-6 [30]. It is also responsible for the biosynthesis of estrogen in adipose tissue in vivo by stimulating aromatase expression [31]. Therefore, there 
could be an increase in circulating TNF- $\alpha$ in obese individuals that could contribute to insulin resistance and in turn may lead to breast tumorigenesis by regulating the synthesis of IL-6. IL-6 acts both locally and in other parts through circulation and is secreted by adipocytes. It has been reported that the expression of IL-6 and plasma levels are elevated in adipose tissue of individuals with obesity and insulin resistance [32,33]. It has been proposed that IL-6, along with Leptin, is responsible for the regulation of energy balance by conveying information to the hypothalamus from adipocytes. IL-6 has been reported to be an inhibitor in early-stage breast cancer, however high serum level of IL-6 is associated with poor prognosis in metastatic breast cancer in advanced stages. IL-6 is also known to stimulate aromatase expression in adipose tissue in vitro and in vivo, thereby stimulating estrogen biosynthesis [34], and possibly directly contributing to breast cancer progression.

As adipose tissue expands in obesity, levels of these adipokines increase in blood and risks of several cancers grow $[35,36]$. TNF- $\alpha$ levels have been directly correlated with higher body mass index. TNF- $\alpha$ has regulatory effects on several other adipokines and collectively they can promote oncogenesis through inducing cell survival. TNF- $\alpha$ also has anti-apoptotic potential in some tumors through stimulation of NF- $\kappa$ B. Higher level of insulin in circulation promotes higher levels of IL- 6 and TNF- $\beta$ in adipose tissues. Higher levels of IL-6 have been observed in patients with hepatocellular carcinoma and ovarian cancer. IL-6 seems to act through the activation of the JAK/STAT pathway, one of the most important pathways in regulating proliferation and anti-apoptotic actions in tumor cells $[37,38]$. IL- 6 also acts on the PI3K-AKT-mTOR pathway and that increases the expression of cyclin D1, a cell survivor factor [39]. Chronic inflammation has been implicated in the initiation and progression of tumors, through the elevated levels of cytokines like TNF- $\alpha$ and IL-6. Systematic inflammation is one of the major causes of colorectal adenoma $[40,41]$.

Mutations in leptin receptor gene or leptine gene may result in aberrant leptine action and may result in obesity and obesity related diseases [42]. Investigations in human tumor cell lines and mouse models indicate that leptine balance has an effect on pathways that regulate growth, including NF- $\kappa$ B, PI3K-AKT-mTOR and JAK/STAT $[43,44]$. In recent research, synthetic nanopeptides have been observed to block leptine effects and as a result interfere with these pathways both in vitro and in vivo. The leptin levels are higher among obese individuals compared to their leaner counterparts. This indicates a correlation of leptine levels with the total body fat, and increases the risk of several cancers. For example postmenopausal women with higher body fats have the highest risk for breast cancer [45].

The Janus kinase/signal transducerandactivator of transcription (Jak/Stat) pathway is a mediator of cytokine signaling. The Jak/Stat pathway is central to the signalling by various cytokine receptor systems and regulates various fundamental cell functions. IL-6mediated activation of Stat3 is a principal pathway implicated in promoting tumorigenesis [46]. Aberrant activation of this pathway results in neoplastic transformation and abnormal growth in malignancies e.g., breast cancer. It is unclear how Jak/Stat pathway modulates the pathogenesis of breast cancer. Vascular endothelial growth factor (VEGF), a key angiogenic factor is an important biological marker for breast cancer malignancy and progression [47], which is controlled by pro-inflammatory cytokines like TNF- $\alpha$. Obesity has been reported to increase tumor growth rate by upregulation of VEGF pathways $[48,49]$. Obesity is an independent prognostic factor for the development of metastases after breast cancer diagnosis [50]. Leptin, the main adipokine secreted by adipose tissue, is also abnormally expressed by breast cancer cells [51]. The metastatic proteins matrix metalloproteinases (MMPs), particularly MMP-2 and MMP-9 are regulated by Leptin, as evident by the decrease in these two metastatic proteins following Leptin knockdown [52].

Recative oxygen species (ROS) cause inflammation which is a cause for many types of cancer. It has been observed that elevated levels of insulin increased mitochondrial generation of Reactive oxygen species (ROS) in several cancer cell lines [53]. These elevated levels of ROS cause DNA damage that further exacerbates carcinogenesis. It has also been observed that high-fat diets induce obesity and serve as tumor promoters, resulting in increased number of tumors, as well as larger tumors [54]. This may also cause a higher level of metastasis. The mutation in the Pac gene in mouse provides a suitable model for studying increased levels of colon cancer due to hereditary causes in humans. High fat diets in the mouse model have been observed to induce inflammation through up-regulation of the NF- $\kappa$ B pathway.

\section{Some important pathways implicated in obesity}

PI3K-AKT-mTOR is an intracellular pathway that does not depend on any extracellular signalling $[55,56]$. The main purpose of this pathway is to regulate cell cycle and control cellular proliferation. This pathway is overactive in many cancers by suppressing apoptosis, and increasing cell proliferation, the two major hallmarks of cancer. PI3K are lipid kinases that phosphorylate PIP2 into PIP3. The action of PIP3 is to activate kinases with the pleckstrin homology domain or PH. An example of such a kinase is PDK1. PTEN inhibits PI3K by controlling the signalling of PIP3. AKT also has a PH domain, and is activated by PDK1 and mTORC2. AKT is capable of phosphorylating many target proteins including AKT1S1, GSK3 and TSC2. Hence, AKT has extensive downstream effects and can control apoptosis and cell proliferation. This pathway is active in ovarian, breast and urothelial cancers.

The signal for the Ras-Raf-MEK-MAPK pathway comes from outside a cell, and eventually reaches the nucleus [57]. Mitogens are the signalling molecules for controlling cell division and proliferation. An example of a mitogen is the EGF (epidermal growth factor). The main molecules involved in this pathway are Ras, RTK, MEK, RAF and ERK. The receptor EGFR binds to the external signalling molecule EGF. This is the activation signal for the pathway. The next step is the phosphorylation of EGFR and the binding of a complex of the docking protein SOS and GRB2 to the phosphorylated EGFR. This activates SOS and the action of SOS is to remove GDP from members of the Ras family of proteins. As a result, Ras binds to GTP, and activates the RAF kinase. RAF 
phosphorylates MEK, which in turn phosphorylates MAPK. MAPK then phosphorylates several transcription factors, which in turn regulate the transcription of several genes that control the cell cycle progression.

JAK/STAT is a complex signalling pathway involving many proteins. It is activated by extracellular ligands and the signal is finally communicated to the nucleus where transcription factors regulate gene expression. This pathway is involved in cell cycle progression, apoptosis and tumor formation and progression, and as mentioned before, a disruption of this pathway has been implicated in several cancers. Our brief review of this pathway is based on the paper by Schindler et al. [58]. The main players in this pathway are the four JAK proteins, JAK1-3 and TYK2; and the seven STAT proteins, STAT1-4, STAT5A, STAT5B and STAT6. Cytokines like IL-6 first binds to cell surface receptor and dimerize the receptors. This results in the JAK proteins to come in contact with the receptors, and the JAK proteins phosphorylate each other through a process called transphosphorylation. The phosphorylation occurs on the tyrosine residues of the JAKs, and increases the activity of their kinase domains. In the next step, the JAKs phosphorylate the tyrosine residues of the receptor and this creates binding sites for the SH2 domains of the STAT proteins. Once the STATs bind to the receptor, the JAKs tyrosine-phosphorylate them and this causes the STATs to disassociate from the receptors. The SH2 domain of a STAT binds to the phosphorylated tyrosine of the opposite STAT, forming a dimer. This dimer translocates to the nucleus and acts as transcription factor for the target genes.

The Keap1-Nrf2 pathway is triggered due to excessive oxidative stress $[59,60]$. The important participants in this pathway are Kelchlike ECH-associated protein (Keap1) and antioxidant response elements (ARE). AREs are usually sequences in the untranslated regions of genes and act as regulatory elements for transcription. Nuclear factor-like 2, or Nrf2 regulates as a transcription factor the transcription of the proteins that are responsible for controlling oxidative damage. Nrf2 is kept in the cytoplasm as a complex by several proteins including Keap1 and Cullin3, and the average lifetime of Nrf2 is very short when there is no oxidative stress. $\mathrm{Nrf} 2$ is degraded fairly quickly through ubiquitination by Keap1 and Cullin3 in unstressed conditions. However, if there is oxidative stress in the cell, the Keap1-Cullin3 complex is disrupted and Nrf2 is not ubiquitinated anymore and released in the cytoplasm. Nrf2 is then transported to the nucleus and binds to the ARE in the promoter regions of the target antioxidative genes, resulting in the increased transcription of these genes.

\section{Phytochemicals in Obesity Control}

There are a number of ways obesity can be controlled. The first approach is lifestyle change, which includes proper diet and exercise. Physical exercise results in diminished body fat owing to enhanced fat burning, which is nothing but fatty acid oxidation [61]. Exercise affects fatty acid oxidation and the rate depends on the extent of physical exercise. For low to moderate exercise, fatty acid oxidation in elevated, while for higher exercise, the level drops [62]. With increasing intensity of exercise, carbohydrate oxidation yields more energy. With enhanced duration of exercise, the energy rate from fatty acid oxidation increases. If the exercise is continued, breakdown of muscle glycogen is achieved. Hence, in order to achieve maximum weight loss, duration of exercise should be more, but moderate intensity exercise is recommended [63].

Efficient fat burning is the primary goal of treating or preventing obesity. Bariatric surgery, intragastric balloon and metabolic surgical procedures are sometimes done for an effective treatment. When lifestyle modifications like more exercise and less intake of food fail to control obesity, pharmacotherapy may help $[64,65]$.

\section{Drugs for controlling obesity}

A number of drugs have been developed for controlling obesity. The drugs commercially available are Orlistat, Lorcaserin, Sibutramine, Rimonabant, Metformin, Exenatide and Pramlintide. Antiobesity drugs can be broadly divided into two categories. The first category acts centrally by repression of appetite. The second category acts peripherally through suppression of fat absorption. Phentermine and Sibutramine are the centrally acting drugs. The peripherally acting drugs are Benzphetamine, Diethylpropion, Phendimetrazine, Orlistat, Mitratapide, Dirlotapide etc. [66]. Orlistat, a pancreatic lipase inhibitor breaks down dietary fats to free fatty acids, preventing absorption of ingested fats. However, this formulation has certain side effects including gastro-intestinal problems like oily stool, urgency and incontinence of stool. Another drug is Liranglutide, which is a glucagon-like peptide- 1 receptor agonist. The side effects include gastrointestinal irritation and may lead to acute pancreatitis. Lorcaserin, a serotonin agonist has been found to subdue appetite. A combination of Phentermine and Topiramate facilitates weight loss by enhanced burning of energy [67]. Phentermine is apparently a safe drug but not much effective [68]. Some other drugs are Amfepramone, Naltrexone/bupruprion etc. [69].

There are some adverse effects of bariatric surgery, including acute pancreatitis, deep vein thrombosis, hernia and infections [70,71]. Often combination therapeutics are used to prevent weight gain. Some such combinations are Contrave (Bupropion + Naltrexone), Empatic (Bupropion + Zonisamide), Qnexa (Topiramate + Phentermine) [72]. Most of the antiobesity drugs have been withdrawn due to serious side effects. Fenfluramine and Dexfenfluramine, serotonin releasing agents have been withdrawn from the market due to heart valve damage, headache, diarrhoea, dizziness, dry mouth, insomnia, erectile dysfunction, anxiety, irritability, lethargy, and CNS stimulation [73]. Rimonabant, an anorectic antiobesity drug has several side effects, like increased risk of serious psychiatric disorders including, depression, anxiety, and suicidal attempts [74]. Therefore, it is apparent that conventional obesity control measures often show various problems, both physical and psychological. Therefore, there is an urgency to consider some unconventional treatments.

\section{Phytochemicals in obesity control}

Considering the side-effects of the antiobesity drugs, a holistic approach can be of much help in obesity control. We consume a 
lot of fruits and vegetables with our daily meals, containing many beneficial chemical compounds. These plant derived molecules with therapeutic activities are coined as phytochemicals and many of them like Withaniasomnifera, Zingiberofficinale, Dioscoreanipponica, Maludomestica, Nelumbonucifera, Cassia nomame etc. have elicited antiobesity properties [66]. Phytochemicals can be classified into different groups. These are broadly alkaloids, carotenoids, nitrogen containing compounds and organosulfur compounds and phenolics. Phenolics consist of phenolic acids, tannins, stilbenes, coumarins and flavonoids. Flavonoids comprise anthocyanidins, flavan-3-ols, flavonols, flavones, flavanones, isoflavones. Alkaloids may be heterocyclic or non-heterocyclic [19]. Examples of some other phytochemicals are glucosinolates (isothiocyanates and indoles), phytates and phytoestrogens (isoflavones and lignans).

Phytochemicals have a number of health promoting activities They are anticarcinogenic, antimutagenic, antioxidant and antiinflammatory, besides having other beneficial attributes. Fruits, vegetables and spices are good sources of phytochemicals, dietary fibres, and they are low in energy density and impart protection against obesity [75]. The bioactive chemical compounds present in the phytochemicals have minimal energy value. They are also beneficial in weight management and obesity prevention [76,77]. They suppress appetite, mainly by targeting gut-derived hormones, also called GLP-1 or ghrelin [78,79]. Receptors of the neuronal system, i.e. transient receptor potential cation channel subfamily $\mathrm{V}$ member 1 (TRPV1) is another target [80]. A constant feeling of hunger is one of the symptoms of obesity that tempts one to consume more food, and hence eventually may cause obesity. Some plant derived products may help in suppressing this nagging hunger and hence help in achieving weight loss [4]. Some of the possible rudimentary justification for obese condition may be inhibition of absorption of fat, impediment of pre-adiposyte differentiation, lipolysis stimulation and induction of apoptosis of adipocytes [63]. Oxidation of fatty acids by phytochemicals may be another reason for their beneficial effects $[81,82]$.

Phytochemicals with antiobesity potential may be an alternate way to reduce body weight and control adipose tissue mass [63]. Not only adipose tissue growth, differentiation of pre-adipocytes and hunger or appetite may be altered by phytochemicals. All these facilitate loss of weight and hence control obesity $[83,84]$. Like physical exercise, phytochemical consumption has an effect on fatty acid oxidation and thus they burn fat. There may be an additive effect of phytochemicals and physical exercise on fatty acid oxidation. Apart from being good anticancer agents, isothiocyanates can prevent conversion of sugar and carbohydrates into fat. Hence cruciferous vegetables containing isothiocyanates are promising antiobesity agents [85]. The phytochemicals contained in fruits, vegetables, and other plant parts show anti-inflammatory effect [86]. This anti-inflammatory property may contribute to combat the obesogenic state [77]. One unique feature of phytochemicals is that they aim to target the pathways related to obesity [87].

The metabolic properties of an adipocyte vary during its life cycle. Upon maturation, adipocytes accumulate triglyceride and grow in size. The rate of triglyceride synthesis is more in larger adipocytes. This leads to higher rate of fatty acid flux. Secretion of cytokines is dependent on the size of adipocytes. Larger is the size of adipocytes, profile of cytokine secretion is unfavourable, hence smaller adipocytes are better. The metabolic consequences of obesity are dependent on whether expansion of adipose tissue is achieved primarily by an increase in adipocyte number or adipocyte size [88]. Phytochemicals may act on different stages of the life cycle of adipocytes. Phytochemicals elicit their function via inhibition of cell proliferation and enhancement of programme cell death of fat cells. They also inhibit the absorption of triglyceride [77], hinder the absorption of lipid, reduce the intake of energy and they help to expend more energy. Another beneficial effect is the inhibition of lipogenesis [89]. Phytochemical index is a good measure to assess the role of a particular compound in obesity control. The ratio of the energy obtained from diet and the energy expended per day is called the phytochemical index, which maintains an inverse relation with adiposity and oxidative stress [90].

A cluster of conditions that increases probability of heart disease, stroke, type 2 diabetes, hypertension, high blood sugar, pot belly (excess of body fat around waist), dyslipidaemia (abnormal cholesterol) and hyper-triglyceredimia (high triglyceride levels) is coined as metabolic syndrome (MS). Both obesity and MS have a high mortality rate. MS has increased globally and this is a serious problem, which needs urgent attention. MS and inflammation are intimately connected. Intestine, liver and adipose tissues are the sites where inflammation is initiated in MS. Due to hypertrophy of adipocytes, adipose tissues induce a pro-inflammatory state [91]. Proinflammatory cytokines like tumor necrosis factor alpha (TNF- $\alpha$ ), IL-6, IL-8 and the chemokine ligand 2, also called monocyte chemoattractant protein 1 (MCP-1) are secreted by hypertrophic adipocytes. These proinflammatory cytokines lead to serine phosphorylation of insulin receptor substrate- 1 by nuclear factor $\mathrm{kB}(\mathrm{NF}-\mathrm{kB})$ and Jun N-terminal kinase (JNK) signalling [92]. Adipocyte hypertrophy leads to hypoxic condition, thereby inducing cell necrosis. This facilitates production of TNF- $\alpha$, IL-6, plasminogen activator inhibitor-1 (PAI-1) and infiltration of macrophage [93]. TNF- $\alpha$ leads to enhancement of insulin resistance in adipose cells. Therefore, MS needs to be considered in obesity control. Treatment of MS involves lifestyle modifications, which include proper diet and regular physical activity.

Metabolic syndrome (MS) may be treated with a number of polyphenols present in food, including green tea, many types of nuts, red wine, grape seeds, berries and dark chocolate etc. Catechins in green tea is a flavanol and caffeine is an alkaloid, both show metabolic effects. The polyphenols in green tea include epicatechin (EC), epicatechin gallate (ECG), epigallocatechin (EGC), and epigallocatechin gallate (EGCG). Treatment with green tea aids in reduction of body weight, it also controls waist circumference and body fat mass [94]. Caffeine increases energy expenditure and diminishes energy intake, thereby affecting energy balance [95]. Tea shows some antiobesity effects due to the presence of catechins and caffeine, which act on the adrenergic system. The phosphodiester enzyme which facilitates hydrolysis of cyclic 
adenosine monophosphate (cAMP) to AMP is inhibited by the purine alkaloid caffeine. Upon activation, cAMP signal induces adrenergic effect that includes reduction of hunger, and enhancement of energy expenditure and lipolysis [96]. The active ingredient in green tea induces overstimulation of the adrenergic system. All these lead to enhanced expenditure of energy, oxidation of fats and lipolysis [97]. It has been reported that the effect of green tea on energy expenditure is higher in the presence of caffeine [91]. Green tea lessens oxidative stress due to cardiac remodelling in patients undergoing dialysis $[91,98]$. Inflammation in the nervous system is also reduced by green tea [99]. Consumption of green tea results in fullness and satiety [100]. Green tea polyphenol EGCG has been found to inhibit adipogenesis. Some other natural biomolecules that also aid in inhibition of adipogenesis are genistein, resveratrol, capsaicin, and procyanidins [101]. EGCG has been found to diminish hunger and increase fullness; however satiety remains unaltered after daily intake of $1796 \mathrm{mg}$ of the polyphenol for 3 weeks [102]. Another report says that $100 \mathrm{mg}$ of EGCG consumption for 2 months increased satiety and fullness, concomitantly decreasing hunger [103]. Fatty acid oxidation can be greatly increased by EGCG. These catechins also enhance the fat burning index, which is measured by the indirect calorimetry methodology and is indicated by a reduction in the respiratory exchange ratio, designated as RER [63]. The mechanism by which green tea shows its antiobesity action may be through the inhibition of catechol-0-methyltransferase (COMT), an enzyme that degrades norepinephrine. Higher concentration of norepinephrine elevates thermogenesis and fat oxidation, thereby reducing appetite [4].

The delicious Capsicum pepper is very popular and can be eaten raw or cooked. It is a genus of flowering plants in the nightshade family Solanaceae. Some members of this family are used as spices and vegetables. Its medicinal attributes are also well-known. The pungency is due to the presence of Capsacinoids, which have been reported to increase satiety [4]. A study conducted with a capsicum analog nonivamide revealed that its intake diminished the feelings of hunger for several hours [104]. The active ingredient Capsaicin in capsicum controls obesity by burning more calories vis enhancement of metabolism [105]. One of the mechanisms by which capsaicin promotes satiety is by enhancing gastrointestinal distress and feeling of bloating [78]. A diet rich in red pepper (cayenne) has been found to increase the concentrations of glucagon-like peptide-1 (GLP-1) and reduce the concentration of ghrelin. Glucagon like peptide 1 is produced in the ileum and colon and regulates appetite and food intake, it also acts as an anorexigenic hormone [4]. Capsacinoids suppress appetite via interference with sympathetic nervous system (SNS). They enhance catecholamine secretion, which results in a reduction in appetite $[106,107]$. Both capsicum and green tea can fight obesity. Hence a combination of these two may be more effective. Keeping this in mind, trials have been undertaken to assess the efficacy of this combinatorial treatment in obesity control. Randomized controlled trials have reported that catechins in green tea, together with capsaicin appreciably diminished hunger and enhanced fullness and satiety [102].
Caralluma adscendens var. fimbiata is a medicinal plant that contains glycosides, flavonoids and steroids and shows a number of benefits. It acts as an anti-inflammatory, antioxidant, anti-diabetic, analgesic, anti ulcer, antibacterial and hypoglycemic molecule. This plant finds use for its antiobesity properties [108] as well as its ability to reduce hunger levels [109]. Another group of polyphenols, well-known for their antioxidant properties is Anthocyanins, which are water soluble. These are found in red wine, fruits that are red or purple in color, some vegetables like cabbage, grapes, strawberries, cranberries, cherries, apples, beets and cereals. These are good antioxidants owing to their property to transfer electrons or to donate the hydrogen atoms to free radicals from different hydroxyl groups [110]. Anthocyanins are anti-inflammatory; they are also good anti-carcinogenic, anti-convulsant and anti-diabetic. Growth of adipose tissues is negatively influenced by Anthocyanins. Lipolysis is increased, along with fat mobilisation and fatty acid oxidation [111-116]. Berries rich in anthocyanins break down fats and sugars and thus curb extra fat [117]. In vivo studies also reveal that these compounds help in reducing body weight and accumulation of adipose tissues; therefore they play a vital role in obesity control. Anthocyanins regulate fatty acid oxidation by upregulation of AMPactivated protein kinase (AMPK) and downregulation of carnitine palmiyoyltranferase-1 (CPT-1) [117].

Another important polyphenol is resveratrol, which is found in abundance in red grapes, apples, peanuts, blueberries and cranberries. Resveratrol has been found to inhibit adipogenesis and preadipocytes. It does so via down regulation of adipocyte specific gene expression. Resveratrol aims at various molecular targets and decreases the number of adipocytes. This polyphenol upregulates AMPK and down regulates PPAR- $\alpha$ and thereby enhances oxidation of fatty acids [63]. Blueberries control triglycerides, weight gain, liver weight and abdominal fat mass. Besides, they aid in improving adipose and skeletal muscle PPAR activitiy, which is responsible for uptake of glucose and oxidation of fats [118]. Strawberry consumption has been found to decrease total cholesterol and small low-density lipoprotein particles. Apples and blackcurrants have been found to decrease postprandial glucose and insulin via inhibition of intestinal glucose transport [91].

Another important phenolic acid is Synephrine, which is present in bitter orange. It primarily exists in protoalkaloid form and is well known for its weight control properties [119]. This compound increases the resting expenditure of energy, lipolysis and fat breakdown during resting phase [63]. Thermogenic effects of this plant molecule are due to activation of $\beta$-adrenergic receptor [120]. Another fruit with a lot of health benefits is pomegranate. This fruit also contains polyphenols ellagitannins, anthocyanins etc. It has been found to decrease blood glucose and enhance insulin sensitivity among other benefits. This fruit show its antiinflammatory effects, through the PPAR pathway. The dried and fermented seed of Theobroma cacao is cocoa, which is very popular among the chocolate lovers. It imparts a cardioprotective effect. Among many other attributes, cocoa finds use in glucose control. It can improve MS via several mechanisms, including inhibition of digestive enzymes. Olea europaea or olive is a subtropical evergreen 
tree with edible fruit. It is an integral part of Mediterranean diet. Olives contain anti-inflammatory agents and improve blood pressure, glycaemic control, endothelial function and oxidative stress. Oil made from olive is therefore good for our health.

An important phytochemical that finds place in our food is turmeric, whose active ingredient is curcumin. It has a wide range of beneficial attributes, e.g., it has anti-inflammatory, hypoglycemic, antioxidant, antiviral and antimicrobial activities. It is also stud with anticancer potential. It shows effect on signalling molecules implicated in inflammation and cancer. Activity of different transcription factors, growth factors, inflammatory cytokines, protein kinase and other enzymes are modulated by curcumin. Curcumin reduces low density lipoprotein (LDL) or the bad cholesterol and at the same time controls hypertension [121]. It has impact on weight, glucose and lipid profile, in patients with MS [122]. Another herb cardamom burns fat. Two other spices cinnamon and clove increase insulin function, reduce glucose, total cholesterol and thus help to control obesity $[123,124]$.

There are a number of other plant derived products that aid in obesity control. Among the fruits that help to curb obesity are watermelon, avocado, apple, blueberry, cucumber, orange, quinoa, grapefruit, pear, zizyphus (Indian plum) etc. Vegetables are also equally effective in obesity related diseases. Curry leaves, cabbage, garlic, ginger, green leafy vegetables like spinach, beans, tomato, broccoli, spring vegetables like asparagus etc aid in obesity management. Allicin in garlic reduce cholesterol and unhealthy fats. Besides pulses, millets such as jowar, bajra, ragi, oats etc. are effective in obesity control Normally it is thought that intake of nuts can cause obesity since they are energy rich food. At the same time nuts contain good amount of fibre. Presence of fibres gives a sense of satiety, which plays a role in weight management. Nuts like almond are rich in vitamin E. Peanuts also show favourable lipid and lipoprotein profiles that help in weight control [105]. Antioxidant lycopene rich tomatoes are stud with a number of health benefits. These include less risk of heart disease and cancer. Besides, tomato contains vitamin $\mathrm{C}$, folate, potassium and vitamin $\mathrm{K}$ and helps to control obesity [125].

Cooking without brushing the pan with oil is practically impossible. Oils and fats give a good tone and texture to the skin, but a diet containing high amount of unhealthy fats can cause obesity. However, there are some oils that can combat obesity, including coconut oil, mustard oil and olive oil. Mustard oil extracted from the seeds of mustard is rich in fatty acid, oleic acid, erucic acid and linoleic acid and contains low amount of saturated fat. Mustard oil also contains Diacylglyecerol, which is responsible for its antiobesogenic effect [126]. Coconut oil is used for preparing food and contains more than $65 \%$ medium-chain fats, due to which thermogenesis can be achieved, leading to obesity control. Coconut oil increases the high-density lipoprotein (HDL) level, thereby improving the LDL/HDL ratio. Therefore, it has an impact on BMI [127]. Olive oil is good for cooking and it is also used as a good salad dressing. Medium chain fatty acids present in it results in thermogenesis and is known for its antiobesity attributes [128].
Tea seed oil contains monounsaturated fatty acids and can prevent obesity [129]. Antiobesity effects are mediated through their anti-lipase activity, anti-hyperlipidemia etc. These oils inhibit adipogenetic transcription factors including PPAR $\gamma$ and CEBP $\alpha$ at the protein and mRNA level. Plasma glycerol concentration is increased, which is a marker of lipolysis and intracellular triglyceride and fat accumulation is also diminished by the essential oils [130]. Herbs and spices are often effective in obesity control. They inhibit lipase, down-regulate adipogenesis and thermogenesis. They also affect lipid metabolism and regulate a number of signal transduction pathways implicated in obesity. Antiobesity herbs include Acacia arabica, Aconitum heterophyllum, Aloe vera, Azadirachta indica, Betula utilis, Calatropis gigantean, Cinnamomum zeylanicum, Emblica officinalis, Moringa oleifera and many others [89].

Some other vegetables that we consume have promising potential. Spinach is a leafy vegetable, rich in chlorophyll, antioxidant phyto-constituents such as flavonoids, polyphenols, carotenoids and vitamins. It is very effective in controlling obesity caused due to high fat diets. It aids in reduction of water retention in our body [131]. Beans being low in fat and abundant in fiber increase satiety, but do not add much calorie to a diet [132]. Green coffee bean has been found to regulate body fat in high fat diet induced obesity. These beans have been found to reduce weight, fat mass, size of adipocytes and plasma lipid level. These have been achieved via regulation of adipogenesis and lipogenesis [133]. Two other phytochemicals asparagus and Jerusalem artichokes, rich in dietary fibres are capable of fighting obesity as well as getting rid of toxins and other wastes from the body [134]

Dietary fiber or roughage are found in edible plant foods such as cereals, fruits, vegetables, dried peas, nuts, lentils and grains. These fibers may be in soluble or insoluble forms, of which insoluble forms work better in controlling obesity than the soluble ones [135]. As they remain undigested, they help to relieve constipation and they control hunger by boosting up metabolism. Oats contain good antioxidants and minerals. The fibres in oats bring down cholesterol levels and control obesity. Millets also contain fibres, which absorb cholesterol, enhance bile secretion, emulsify fats and thereby reduce weight [136]. Consumption of dietary fibers is important in preventing MS and obesity. Some fruits like apples, and avocados contain high amount of fibre and other nutrients. Regular consumption of apples, avocados increases satiety, hence appetite is decreased and so is obesity [105]. Apart from being rich in fiber, avocados contain high amount of monounsaturated fatty acid (MUFA), and are one of the highest sources of beta-sitosterol, which inhibits cholesterol [137].

As mentioned before, exercise is one of the key ways to achieve weight loss. Exercise, along with generous consumption of phytochemical may show some add-on effect on fatty acid oxidation. Consumption of Catechins from green tea along with exercise showed an additive effect on fatty acid oxidation rate and lipolysis [138]. Similar findings have been reported in case of p-synephrine and exercise. However, anthocyanins along with exercise did not show any promising outcome, only an accumulative effect 
was seen [116]. For many phytochemicals, bioavailability is a big problem, and that could be one of the reasons why additive effects were not seen in case of anthocyanins and exercise. Nature of the phytochemicals and their mode of action on different molecular targets may be some other determining factors for their efficacy. EGCG along with exercise increases fat oxidation rate, fat utilization, plasma glycerol and epinephrine, while respiratory exchange ratio (RER) gets diminished. Resveratrol along with exercise enhances fat oxidation and decreases RER. P-synephrine increases oxidation of fat, when taken in combination with exercise. All these plant molecules have different modes of action. Combination of more than one phytochemical in aid of obesity control has been reported. Resveratrol in conjunction with genestein and quercetin caused a marked decrease in the process of adipogenesis. Resveratrol in cooperation with vitamin D has been found to prevent extra weight gain [139]. Thus, resveratrol along with other phytochemicals or physical exercise may serve as a good candidate in obesity control.

\section{Phytochemicals in obesity related cancers}

Phenolic phytochemicals have strong antioxidant activities due to the phenolic hydroxyl groups providing hydrogen atoms for capturing reactive oxygen species (ROS). Excessive oxidative stress is mainly due to $\mathrm{H} 2 \mathrm{O} 2$ and $\mathrm{OH}$ and these agents are responsible for cancer cell proliferation. Phenolic phytochemicals can inhibit the effects of $\mathrm{H} 2 \mathrm{O} 2$ by intervening in several pathways including NF- $\kappa \mathrm{B}$ and MAPK. Epigallocatechin gallate (EGCG) is a phenolic phytochemical present in green tea and has very effective antioxidant effects. The effect of EGCG on human epidermal keratinocytes has been observed by inducing oxidative stress through ultraviolet radiation, as UV radiation increases the concentration of $\mathrm{H} 2 \mathrm{O} 2$. This in turn increases the phosphorylation of JNK and MAPK. It was observed that EGCG could inhibit MAPK activation by scavenging of H2O2 [140]. TNF triggers $\kappa$ activation. In another study Manna et al. [141] showed that resveratrol, the phenolic phytochemical found in grapes, prevented NF- $\kappa \mathrm{B}$ activation in several cell lines, including Jurkat, HeLa and U-937. Yu et al. [142] showed similar results in HeLa cell lines. Isothiocyanates also have antioxidant properties as well as peroxidant properties [143]. There are many other natural phytochemicals, that act as good antioxidants and help in obesity related cancers. Lycopene, a carotenoid is found in fruits and vegetables having red color, particularly tomatoes. Phloretin, a flavonoid is found in apples. Another flavonoid of importance is kaempferol, found in kale, beans, spinach and broccoli etc. All these three contribute as anticancer, anti-diabetic and anti-obesogenic agents [144]. Quercetin, a flavonoid is found in onions, green tea, apples, berries, St. John's wort, buckwheat tea etc. Quercetin is an antioxidant that aids in obesity and cancer. Some other antioxidant phytochemicals that contribute in this regard are naringenin, a flavonoid, flavones like luteolin, daidzein, genestein etc. Allicin, an organosulfur compound, phenolic acids like caffeic acid, chlorogenic acid, ferulic acid, tannins are good anti-obesogenic and anti-cancer agents [144].

ROS impacts activation of transcription factors like Activator Protein-1 (AP-1) or NF- $\kappa$ B. These in turn can modulate proinflammatory cytokines such as Tumor Necrosis Factor $\alpha$
(TNF- $\alpha$ ), Interleukins like IL-6, IL-8, and IL-1 [145]. Glycosides of apigenin, leuteolin are anti-inflammatory and can work in this regard. Apigenin is capable of suppressing nitric oxide (NO) via inhibition of inducible nitric oxide synthase (iNOS) and COX-2 [146]. Luteolin is capable of inhibiting inflammation of adipocytes. Inflammation in macrophages and phosphorylation of JNK in macrophages can be inhibited by luteolin. Quercetin, found in abundance in apples, isoflavones like genestein, daidzein, glycitein show their anti-inflammatory properties via modulation of NF- $\kappa$ B. These compounds have been found to downregulate TNF- $\alpha$ and IL-6. Anthocyanins are good anti-inflammatory molecules that works through mitogen activated protein kinase (MAPK) pathway. Glycosides of malvidin, delphinidin, cyanidin, petunidin, and peonidin can inhibit IL-1 $\beta$-activation of NF- $\mathrm{B}$ [147]. Licorice roots contain triterpenes like glycyrrhizin and glycyrrhetinic acid, which are also promising anti-inflammatory agents. They act through P13K/Akt/GSK3- $\beta$ pathway to reduce cytokine production [146].

Polyphenols like curcumin, genistein and epigallocatechin are particularly effective in this respect for mitigating the effects of obesity related tumor onset and progression. Curcumin is a lipophylic polyphenol and a popular Indian spice. The effect of curcumin on the Nrf2 pathway has been studied [143,148]. Das and Vinayak [148] studied the effect of Nrf2 activation on liver cells of mice by inducing Dalton's lymphoma. When lymphoma was progressing, the Nrf2 pathway was suppressed, but was restored after administering curcumin through intraperitoneal injections. Chen et al. [149] showed that curcumin had dual effects of increasing the expression of Nrf2 as well as decrease in the expression of Fen1, which is known to be expressed in breast cancer as an endonuclease that cleaves the phosphodiester bonds of DNA. Curcumin has been found to inhibit TNF- $\alpha$, IL-1 $\beta$ and suppress NF$\kappa B[150,151]$. Resveratrol has been found to inhibit all three, in addition this biomolecule also inhibits IL-6 [146]. Rosmarinic acid, from Rosemary and sage are good antioxidants that has effects on these pathways [152].

Plant biomolecules induce the expression of several antioxidant enzymes. They also aid as modifier of a number of signal transduction pathways. This includes suppression of stress induced proteins and Keap1 dissociation from Nrf2 as a consequence of stress is facilitated. EGCG, lycopene, resveratrol, curcumin, mulberry leaf help in this regard by modulation of Nrf2/ARE pathway [153]. Echinacea purpura L, a herbal medicine improves cellular oxidative status and promotes anti-inflammatory activities [154]. As mentioned before, PI3K pathway is one of the most activated pathways in cancer. There is evidence that PI3K/ AKT pathway leads to obesity and type 2 diabetes mellitus [155]. Therefore, it is important to see how and which phytochemicals target this pathway. A wide range of phytochemicals have been found to inhibit PI3K/AKT pathway. These include gingerol, curcumin, diallyl trisulfide, emodin, ginsenoside, plumbagin, apigenin, resveratrol, EGCG, quercetin, fisetin, luteolin, apigenin, indole-3-carbinol, sulforaphane, PEITC, ellagic acid and many more [156]. Another promising therapeutic target in cancer is MAPK. It has been observed that obesity is related to increased level of 
Mitogen-activated Protein Kinase Phosphatase 3 (MKP-3). A direct correlation between diminished level of MKP-3 and adiposity has been observed [157]. A link has been explored between MAPK signalling and endometrial cancer, which is again due to obesity [158]. Among the phytochemicals that target MAPK are soyleaf, isoflavones, resveratrol, caffeic acid, apigenin, quercetin, kaempferol, genistein, triterpenoids [159]. Besides, JNK, phosphor ERK, phosphor AKT are also down regulated.

Two signalling pathways that are highly implicated in solid tumors are Ras-Raf-MEK-ERK and PI3/AKT. RAF kinase is the downstream target for RAS. This facilitates the activation of ERK1/2. Ras/mitogen-activated protein kinase (MAPK) pathway is linked with adipogenicity. Once ERK is activated, it translocates to the nucleus and initiates mitotic clonal expansion in preadipocytes, which is important for adipogenesis [160]. Acacetin is a natural flavonoid which is derived from Robinia p seudoacacia. Acacetin has been studied for its antioxidant and anticancer properties. Jung et al. [161] reviewed its anti-cancer potential and noted its ability to modulate the PI3K-Akt-mToR pathway. Chen et al. [162] have shown the modulating effect of black rice anthocyanins on the RasRaf-MEK-MAPK pathway. Curcumin, diallyl trisulfide, resveratrol, apigenin, sulforaphane etc. help to modulate this pathway [163]. MAPK/ERK pathway is being modulated by silibenin, fisetin, genestein, etc. [164].

\section{Conclusion}

Obesity is one of the most endemic public health problems worldwide, and a risk factor for many diseases including cancer. Controlling obesity through medication and surgical procedures is often fraught with severe side effects. Hence controlling obesity through naturally occurring phytochemicals is one of most effective strategies. We have examined the role of obesity as risk factors for many diseases in this review. We have examined the genes, proteins and genetic pathways that are triggered by obesity and subsequently affect the onset and progression of many diseases. We have also provided a broad review of the phytochemicals that are effective in controlling obesity by acting on the related genes and pathways, with a particular focus on their effects on different types of cancers caused by obesity.

\section{Conflict of Interest}

The authors have no conflict of interest.

\section{References}

1. Yazdi FT, Clee SM, Meyre D (2015) Obesity genetics in mouse and human: Back and forth, and back again. Peer J 3: e856.

2. Bleich S, Cutler D, Murray C, Adams A (2008) Why is the developed world obese? Annual Review of Public Health 29: 273-295.

3. (2011) Oxford Handbook of Medical Sciences. (2 ${ }^{\text {nd }}$ edn), ISBN 9780191652295, Oxford: OUP Oxford, Hyderabad, India, p. 180.

4. Stuby J, Gravestock I, Wolfram E, Pichierri G, Steurer J, et al. (2019) Appetite-suppressing and satiety-increasing bioactive phytochemicals: A systematic review. Nutrients 11(9): 2238.

5. Jarolimova J, Tagoni J, Stern TA (2013) Obesity: Its epidemiology, comorbidities, and management. The Primary Care Companion for CNS Disorders 15(5): PCC.12f01475.
6. Mahmoud A, le Roux CW, Docherty NG (2017) Morbidity and mortality associated with obesity. Ann Transl Med 5(7): 161.

7. Stone TW, McPherson M, Darlington LG (2018) Obesity and cancer: Existing and new hypotheses for a causal connection. EBioMedicine 30: $14-28$.

8. Calle EE, Rodriguez C, Walker-Thurmond K, Thun J (2003) Overweight, obesity, and mortality from cancer in a prospectively studied cohort of US adults. N Engl J Med 348(17): 1625-1638.

9. Hruby A, Hu FB (2015) The epidemiology of obesity: A big picture. Pharmaco Economics 33(7): 673-689.

10. Gregor MF, Hotamisligil GS (2011) Inflammatory mechanisms in obesity. Annual Review of Immunology 29: 415-445.

11. Randi G, Franceschi S, La Vecchia C (2006) Gallbladder cancer worldwide: Geographical distribution and risk factors. International Journal of Cancer 118(7): 1591-1602.

12. Bishayee A (2014) The role of inflammation and liver cancer. Advances in Experimental Medicine and Biology 816: 401-435.

13. Gallagher EJ, Le Roith D (2015) Obesity and diabetes: The increased risk of cancer and cancer-related mortality. Physiological Reviews 95(3): 727-748.

14. Seo BR, Bhardwaj P, Choi S (2015) Obesity-dependent changes in interstitial ECM mechanics promote breast tumorigenesis. Science Translational Medicine 7(301): 301ra130.

15. Roberts L, Dive C, Renehan AG (2010) Biological mechanisms linking obesity and cancer risk: New perspectives. Annual Review of Medicine 61: 301-316.

16. Taniguchi C M, Emanuelli B, Kahn C R (2006) Critical nodes in signalling pathways: Insights into insulin action. Nature Reviews Molecular Cell Biology 7(2): 85-96.

17. Taniguchi CM, Kahn C (2011) Insulin/IGF-1 signaling nodes and their role. In: Fantus IG, Berger NA (Eds.), Springer, New York, USA, pp. 53-76.

18. Babichev Y, Khalid S, Fantus G I (2011) Potential mechanisms linking insulin to cancer. In: Fantus IG, Berger NA (Eds.), Volume 2, Springer, New York, USA, pp. 159-180.

19. Roy M, Datta A (2019) Cancer genetics and therapeutics: Focus on phytochemicals, Springer, New York, USA.

20. Gesta S, Tseng YH, Kahn CR (2007) Developmental origin of fat: Tracking obesity to its source. Cell 131(2): 242-256.

21. Cancello R, Clément K (2006) Is obesity an inflammatory illness? Role of low-grade inflammation and macrophage infiltration in human white adipose tissue. BJOG 113(10): 1141-1147.

22. Redinger R N (2009) Fat storage and the biology of energy expenditure. Translational Res 154(2): 52-60.

23. Balistreri CR, Caruso C, Candore G (2010) The role of adipose tissue and adipokines in obesity-related inflammatory diseases. Mediators Inflamm 2010: 802078.

24. Frühbeck G, Becerril S, Sáinz N, Garrastachu P, García-Velloso MJ (2009) BAT: A new target for human obesity? Trends Pharmacol Sci 30(8): 387-396.

25. Virtanen KA, Lidell ME, Orava J, Heglind M, Westergren R, et al. (2009) Functional brown adipose tissue in healthy adults. N Engl J Med 360(15): 1518-1525.

26. McArdle MA, Finucane OM, Connaughton RM, McMorrow AM, Roche HM (2013) Mechanisms of obesity-induced inflammation and insulin resistance: insights into the emerging role of nutritional strategies. Front Endocrinol (Lausanne) 4: 52.

27. Kim M J, Rangasamy S, Shim Y, Joon MS (2015) Cell lysis-free quantum dot multicolor cellular imaging-based mechanism study for TNF- $\alpha$ induced insulin resistance. J Nanobiotechnol 13: 4. 
28. Hotamisligil GS (2003) Inflammatory pathways and insulin action. Int Obes Relat Metab Disord 27(3): S53-S55.

29. Bulló M, García-Lorda P, Peinado-Onsurbe J, Hernandez M, Del Castillo, et al. (2002) TNFalpha expression of subcutaneous adipose tissue in obese and morbid obese females: relationship to adipocyte LPL activity and leptin synthesis. Int J Obes Relat Metab Disord 26(5): 652-658.

30. Cláudia M, Nascimento OD, Ribeiro EB, Oyama LM (2004) Metabolism and secretory function of white adipose tissue: effect of dietary fat Biochem Biophys Res Commun 313: 702.

31. Kamel M, Shouman S, El-Merzebany M, Kilic G, Veenstra T, et al. (2012) Effect of tumour necrosis factor-alpha on estrogen metabolic pathways in breast cancer cells. J Cancer 3: 310-321.

32. Vozarova B, Weyer C, Hanson K, Tataranni PA, Bogardus C, et al. (2001) Circulating interleukin- 6 in relation to adiposity, insulin action, and insulin secretion. Obes Res 9(7): 414-417.

33. Mohamed-Ali V, Goodrick S, Rawesh A, Katz R, Miles JM, et al. (1997) Subcutaneous adipose tissue releases interleukin-6, but not tumor necrosis factor-alpha, in vivo. J Clin Endocrinol Metab 82(12): 4196-4200.

34. Purohit A, Reed MJ (2002) Regulation of estrogen synthesis in postmenopausal women. Steroids 67(12): 979-983.

35. Hotamisligil GS, Arner P, Caro JF, Atkinson RL, Spiegelman BM (1995) Increased adipose tissue expression of tumor necrosis factor-alpha in human obesity and insulin resistance. J Clin Invest 95(5): 2409-2415.

36. Vendrell J, Broch M, Vilarrasa N, Molina A, Gómez JM, et al. (2004) Resistin, adiponectin, ghrelin, leptin, and proinflammatory cytokines: relationships in obesity. Obes Res 12(6): 962-971.

37. Loffler D, Brocke-Heidrich K, Pfeifer G, Stocsits C, Hackermüller J, et al (2007) Interleukin-6-dependent survival of multiple myeloma cells involves the Stat3-mediated induction of microRNA-21 through a highly conserved enhancer. Blood 110(4): 1330-1333.

38. Wang Y, van Boxel-Dezaire AH, Cheon H, Yang J, Stark GR, et al. (2013) STAT3 activation in response to IL- 6 is prolonged by the binding of IL-6 receptor to EGF receptor. Proc Nat Acad Sci USA 110(42): 16975-16980.

39. Wegiel B, Bjartell A, Culig Z, Persson JL (2008) Interleukin-6 activates PI3K/Akt pathway and regulates cyclin A1 to promote prostate cancer cell survival. Int J Cancer 122(7): 1521-1529.

40. Grivennikov S, Karin E, Terzic J, Mucida D, Yu GY, et al. (2009) IL-6 and Stat3 are required for survival of intestinal epithelial cells and development of colitis-associated cancer. Cancer Cell 15(2): 103-113.

41. Morris PG, Zhou XK, Milne GL, Goldstein D, Hawks LC, et al. (2013) Increased levels of urinary PGE-M, a biomarker of inflammation, occur in association with obesity, aging, and lung metastases in patients with breast cancer. Cancer Prev Res 6(5): 428-436.

42. Halaas JL, Gajiwala KS, Maffei M, Cohen SL, Chait BT, et al. (1995) Weight reducing effects of the plasma protein encoded by the obese gene. Science 269(5223): 543-546.

43. Gonzalez RR, Cherfils S, Escobar M, Yoo JH, Carino C, et al. (2006) Leptin signaling promotes the growth of mammary tumors and increases the expression of vascular endothelial growth factor (VEGF) and its receptor type two (VEGF-R2). J Biol Chem 281(36): 26320-26328.

44. Chen C, Chang YC, Lan MS, Breslin M (2013) Leptin stimulates ovarian cancer cell growth and inhibits apoptosis by increasing cyclin D1 and Mcl-1 expression via the activation of the MEK/ERK1/2 and PI3K/Akt signaling pathways. Int J Oncol 42(3): 1113-1119.

45. Wu MH, Chou YC, Chou WY, Hsu GC, Chu CH, et al. (2009) Circulating levels of leptin, adiposity and breast cancer risk. Br J Cancer 100(4): 578-582.

46. Sansone P, Bromberg J (2012) Targeting the interleukin-6/Jak/stat pathway in human malignancies. J Clin Oncol 30(9): 1005-1014.
47. Gu JW, Young E, Patterson SG, Kristina M, Jeremy W, et al. (2011) Postmenopausal obesity promotes tumor angiogenesis and breast cancer progression in mice. Cancer Biol Ther 11(10): 910-917.

48. Young E, Miele L, Tucker KB, Huang M, Wells J, et al. (2010) SU11248, a selective tyrosine kinases inhibitor suppresses breast tumor angiogenesis and growth via targeting both tumor vasculature and breast cancer cells. Cancer Biology \& Therapy 10(7): 703-711.

49. Brandon EL, Gu JW, Cantwell L, He Z, Wallace G, et al. (2009) Obesity promotes melanoma tumor growth: role of leptin. Cancer Biol Ther 8(19): 1871-1879.

50. Sinicrope FA, Dannenberg AJ (2011) Obesity and breast cancer prognosis: Weight of the evidence. J Clin Oncol 29(1): 4-7.

51. Gonzalez-Perez RR, Lanier V, Newman G (2013) Leptin's pro-angiogenic signature in breast cancer. Cancers (Basel) 5(3): 1140-1162.

52. Cha Y, Kang Y, Moon A (2012) HER2 induces expression of leptin in human breast epithelial cells. BMB Rep 45(12): 719-723.

53. Othman EM, Leyh A, Stopper H (2013) Insulin mediated DNA damage in mammalian colon cells and human lymphocytes in vitro. Mutation Research 745-746: 34-39.

54. Doerner SK, Berger NA (2013) Dietary fats as mediators of obesity, inflammation and cancer. In: Dannenberg AJ, Berger NA (Eds), Springer, New York, USA, pp. 99-132.

55. Hemmings BA, Restuccia DF (2012) PI3K-PKB/AKT pathway. Cold Spring Harb Perspect Biol 4(9): a011189.

56. Wu JSL, Cui W (2016) Proliferation, survival and metabolism: the role of $\mathrm{PI} 3 \mathrm{~K} / \mathrm{AKT} / \mathrm{mTOR}$ signaling in pluripotency and cell fate determination. Development 143(17): 3050-30160.

57. Zhang W, Liu HT (2002) MAPK signaling pathway in the regulation of cell proliferation in mammalian cells. Cell Res 12(1): 9-18.

58. Schindler C, Levy DE, Decker T (2007) JAK-STAT signaling: From interferons to cytokines. J Biol Chem 282(28): 20059-20063.

59. Raghunath A, Sundarraj K, Nagarajan R, Arfuso F, Bian J, et al. (2018) Antioxidant response elements: discovery, classes, regulation and potential applications. Redox Biol 17: 297-314.

60. Nguyen T, Nioi P, Pickett CB (2009) The Nrf2-antioxidant response element signaling pathway and its activation by oxidative stress. J Biol Chem 284(20): 13291-13295.

61. van Loon LJ, Greenhaff PL, Constantin-Teodosiu D, Saris WH, Wagenmakers AJ (2001) The effects of increasing exercise intensity on muscle fuel utilisation in humans. J Physiol 536(Pt 1): 295-304.

62. Spriet LL (2014) New insights into the interaction of carbohydrate and fat metabolism during exercise. Sports Med 44(Supp 1): S87-S96.

63. Kim JH, Park Y (2016) Combined effects of phytochemicals and exercise on fatty acid oxidation. J Exerc Nutrition Biochem 20(4): 20-26.

64. Astell KJ, Mathai ML, Su XQ (2013) Plant extracts with appetite suppressing properties for body weight control: A systematic review of double blind randomized controlled clinical trials. Complement. Ther Med 21(4): 407-416.

65. Ioannides-Demos LL, Proietto J, McNeil JJ (2005) Pharmacotherapy for obesity. Drugs 65(10): 1391-1418.

66. Chopra A, Kaur N, Lalit (2014) Herbal drugs -a promising approach to obesity management. J Res in Pharmaceutical Sc 2: 1-5.

67. Ruban A, Stoenchev K, Ashrafian H, Teare J (2019) Current treatments for obesity. Clinical medicine (London) 19(3): 205-212.

68. Hendricks EJ (2017) Off-label drugs for weight management. Diabetes, metabolic syndrome and obesity: Targets and Therapy 10: 223-234. 
69. Tonstad S, Rössner S, Rissanen A, Astrup A (2016) Medical management of obesity in scandinavia 2016. Obes Med 1: 38-44.

70. Ikramuddin S, Korner J, Lee WJ, Bantle JP, Thomas AJ, et al. (2016) Durability of addition of roux-en-y gastric bypass to lifestyle intervention and medical management in achieving primary treatment goals for uncontrolled type 2 diabetes in mild-to-moderate obesity: A randomized control trial. Diabetes Care 39(9): 1510-1518.

71. Park J Y, Kim YJ (2016) Laparoscopic roux-en-y gastric bypass in obese korean patients: Efficacy and potential adverse events. Surg Today 46(3): 348-355.

72. Valentino MA, Lin JE, Waldman SA (2010) Central and peripheral molecular targets for antiobesity pharmacotherapy. Clin Pharmacol Ther 87(6): 652-662.

73. Dart RC (2004) Medical toxicology. Lippincott Williams \& Wilkins, Pennsylvania, USA, p. 874.

74. Kang JG, Park CY (2012) Anti-obesity drugs: a review about their effects and safety. Diabetes \& Metabolism Journal 36(1): 13-25.

75. Diep CS, Baranowski J, Baranowski T (2015) The impact of fruit and vegetable intake on weight management. Managing and Preventing Obesity, pp. 59-78.

76. Mirmiran P, Bahadoran Z, Golzarand M, Shiva N, Azizi F ( 2012 ) Association between dietary phyto chem ical index and 3-year changes in weight, waist circum ference and body adiposity index in adults: Tehran Lipid and Glucose study. Nutr Metab 9(1): 108.

77. Williams DJ, Edwards D, Hamernig I, Jian L, James AP, et al. ( 2013 ) Vegetables containing phytochemicals with potential anti-obesity properties: A review. Food Research International 52(1): 323-333.

78. van Avesaat M, Troost FJ, Westerterp-Plantenga MS, Helyes Z, Le Roux CW, et al. (2016) Capsaicin-induced satiety is associated with gastrointestinal distress but not with the release of satiety hormones. Am J Clin Nutr 103(2): 305-313.

79. Smeets AJ, Westerterp-Plantenga MS (2009) The acute effects of a lunch containing capsaicin on energy and substrate utilisation, hormones, and satiety. Eur J Nutr 48(4): 229-234.

80. Tominaga M, Tominaga TJ (2005) Structure and function of trpv1. Pflugers Arch 451(1): 143-150.

81. Dulloo AG, Duret C, Rohrer D, Girardier L, Mensi N, et al. (1999) Efficacy of a green tea extract rich in catechin polyphenols and caffeine in increasing 24-h energy expenditure and fat oxidation in humans. Am J Clin Nutr 70(6): 1040-1045.

82. Rumpler W, Seale J, Clevidence B, Judd J, Wiley E, et al. (2001) Oolong tea increases metabolic rate and fat oxidation in men. J Nutr 131(11): 2848-2852.

83. Tucci SA (2010) Phytochemicals in the control of human appetite and body weight. Pharmaceuticals (Basel) 3(3): 748-763.

84. Rupasinghe HP, Sekhon-Loodu S, Mantso T, Panayiotidis MI (2016) Phytochemicals in regulating fatty acid beta-oxidation: Potential underlying mechanisms and their involvement in obesity and weight loss. Pharmacology \& Therapeutics 165: 153-163.

85. Choi, Kim Y, Park S, Lee KW, Park T (2012) Indole-3-carbinol prevents diet-induced obesity through modulation of multiple genes related to adipogenesis, thermogenesis or inflammation in the visceral adipose tissue of mice. J Nutr Biochem 23(12): 1732-1739.

86. Zhu F, Du B, Xu B (2018) Anti-inflammatory effects of phytochemicals from fruits, vegetables, and food legumes: A review. Crit Rev Food Sci Nutr 58(8): 1260-1270.

87. Holubkováa A, Penesováb A, Šturdíka E, Mošovskáa S, Mikušováa L (2012) Phytochemicals with potential effects in metabolic syndrome prevention and therapy . Acta Chimica Slovaca 5(2): 186-199.
88. Smith J, Al-Amri M, Dorairaj P, Sniderman A (2006) The adipocyte life cycle hypothesis. Clin Sci (Lond) 110(1): 1-9.

89. Chandrasekaran CV, Vijayalakshmi MA, Prakash K, Bansal VS, Meenakshi J, et al. (2012) Herbal approach for obesity management. American Journal of Plant Sciences 3: 1003-1014.

90. Vincent HK, Bourguignon CM, Taylor AG (2010) Relationship of the dietary phytochemical index to weight gain, oxidative stress and inflammation in overweight young adults. J Hum Nutr Diet 23(1): 20-29.

91. Francesco Francini-Pesenti, Paolo Spinella, Lorenzo A Calò (2019) Potential role of phytochemicals in metabolic syndrome prevention and therapy. Diabetes, Metabolic Syndrome and Obesity 12: 1987-2002.

92. Hirosumi G, Tuncman L, Chan L, Gorgun CZ, Teoman K, et al. (2002) A central role for JNK in obesity and insulin resistance. Nature 420(6913): 333-336.

93. Marchesini G, Bugianesi E, Forlani G, Cerrelli F, Lenzi M, et al. (2003) Nonalcoholic fatty liver, steatohepatitis, and the metabolic syndrome. Hepatology 37(4): 917-923.

94. Nagao T, Komine Y, Soga S, Meguro S, Tadashi H, et al. (2005) Ingestion of a tea rich in catechins leads to a reduction in body fat and malondialdehyde modified LDL in men. Am J Clin Nutr 81(1): 122-129.

95. Harpaz E, Tamir S, Weinstein A, Weinstein Y (2017)The effect of caffeine on energy balance. J Basic Clin Physiol Pharmacol 28(1): 1-10.

96. Evans BA, Sato M, Sarwar M, Hutchinson DS, Summers RJ (2010) Liganddirected signalling at beta-adrenoceptors. Br J Pharmacol 159(5): 10221038.

97. Diepvens K, Westerterp KR, Westerterp-Plantenga MS (2007) Obesity and thermogenesis related to the consumption of caffeine, ephedrine, capsaicin, and green tea. Am J Physiol Regul Integr Comp Physiol 292(1): 77-85.

98. Chu SL, Fu H, Yang JX, Geng Xin, Pan Duo, et al. (2011) A randomized double-blind placebocontrolled study of Pu'er tea extract on the regulation of metabolic syndrome. Chin J Integr Med 17(7): 492-498.

99. Mandel SA, Weinreb O, Amit T, Youdim MB (2012) Molecular mechanisms of the neuroprotective/neurorescue action of multi-target green teapolyphenols. Front Biosci (Schol Ed) 4: 581-598.

100. Josic J, Olsson AT, Wickeberg J, Lindstedt S, Hlebowicz J (2010) Does green tea affect postprandial glucose, insulin and satiety in healthy subjects: A randomized controlled trial. Nutr J 9: 63.

101. Andersen C, Rayalam S, Della-Fera MA, Baile CA (2010) Phytochemicals and adipogenesis. Biofactors 36(6): 415-422.

102. Reinbach HC, Smeets A, Martinussen T, Moller P, Westerterp-Plantenga MS (2009) Effects of capsaicin, green tea and ch-19 sweet pepper on appetite and energy intake in humans in negative and positive energy balance. Clin Nutr 28(3): 260-265.

103. Rondanelli M, Opizzi A, Solerte SB, Trotti R, Klersy C, et al. (2009) Administration of a dietary supplement (n-oleylphosphatidylethanolamine and epigallocatechin-3-gallate formula) enhances compliance with diet in healthy overweight subjects: A randomized controlled trial. Br J Nutr 101(3): 457-464.

104. Hochkogler CM, Rohm B, Hojdar K, Pignitter M, Widder S, et al. (2014) The capsaicin analog nonivamide decreases total energy intake from a standardized breakfast and enhances plasma serotonin levels in moderately overweight men after administered in an oral glucose tolerance test: A randomized, crossover trial. Mol Nutr Food Res 58(6): 1282-1290.

105. Mukherjee A, Mukherjee S, Biswas J, Roy M (2015) Phytochemicals in obesity control. Int J Curr Micobl Ap Sci 4(4): 558-567.

106. Clapham JC, Arch JR, Tadayyon MJP (2001) Anti-obesity drugs: A critical review of current therapies and future opportunities. Pharmacol Ther 89(1): 81-121. 
107. Whiting S, Derbyshire E, Tiwari BK (2012) Capsaicinoids and capsinoids. A potential role for weight management? A systematic review of the evidence. Appetite 59(2): 341-348.

108. Tambe DA, Chaudhari TB, Chaudhari SR (2010) Phyto-pharmacology of caralluma adscendens roxb: A review Pharmacognosy Journal 2(14): 33-38.

109. Kuriyan R, Raj T, Srinivas SK, Vaz M, Rajendran R, et al. (2007) Effect of caralluma fimbriata extract on appetite, food intake and anthropometry in adult Indian men and women. Appetite 48(3): 338-344.

110. Wang H, Nair M, Strasburg GM, YC Chang, Booren AM, et al. (1999) Antioxidant and antiinflammatory activities of anthocyanins and their aglycon, cyanidin, from tart cherries. J Nat Prod 62(2): 294-296.

111. Jayaprakasam B, Olson LK, Schutzki RE, Tai MH, Nair MG (2006) Amelioration of obesity and glucose intolerance in high-fat-fed C57BL/ 6 mice by anthocyanins and ursolic acid in Cornelian cherry (Cornus mas). J Agric Food Chem 54(1): 243-248.

112. Matsui T, Ueda T, Oki T, Sugita K, Terahara N, et al. (2001) Alphaglucosidase inhibitory action of natural acylated anthocyanins. Survey of natural pigments with potent inhibitory activity. J Agr Food Chem 49(4): 1948-1951.

113. Wu T, Qi X, Liu Y, Guo J, Zhu R, et al. (2013) Dietary supplementation with purified mulberry (Morus australis Poir) anthocyanins suppresses body weight gain in high-fat diet fed C57BL/6 mice. Food Chem 141(1): 482-487.

114. Prior RL, S EW, T RR, Khanal RC, Wu X, et al. (2010) Purified blueberry anthocyanins and blueberry juice alter development of obesity in mice fed an obesogenic high-fat diet. J Agric Food Chem 58(7): 3970-3976.

115. Titta L, Trinei M, Stendardo M, Berniakovich I, Petroni K, et al. (2010) Blood orange juice inhibits fat accumulation in mice. Int J Obes (Lond) 34(3): 578-588.

116. Cook MD, Myers SD, Blacker SD, Willems ME (2015) New Zealand blackcurrant extract improves cycling performance and fat oxidation in cyclists. Eur J Appl Physiol 115(11): 2357-2365.

117. Wu T, Tang Q Gao Z, Yu Z, Song H, et al. (2013) Blueberry and mulberry juice prevent obesity development in C57BL/6 mice. PLoS One 8(10): e77585.

118. Seymour EM, Singer AA, Kirakosyan A, Urcuyo-Llane, Kaufman PB, et al. (2008) Altered hyperlipidemia, hepatic steatosis, and hepatic peroxisome proliferator-activated receptors in rats with intake of tart cherry. J Med Food 11(2): 252-259.

119. Food and Drug Administration, Public Health Service, US Department of Health and Human Services (2004) Dietary supplements containing ephedrine alkaloids adulterated because they present an unreasonable risk; final rule. J Pain Palliat Care Pharmacother 18(3): 95-107.

120. Stohs SJ, Preuss HG, Shara M (2011) A review of the receptor-binding properties of p-synephrine as related to its pharmacological effects. Oxid Med Cell Longev 2011: 482973.

121. Alappat L, Awad AB (2010) Curcumin and obesity: evidence and mechanisms. Nutr Rev 68(12): 729-738.

122. Yang YS, Su YF, Yang W, Lee YH, Chou JI, et al. (2014) Lipidlowering effects of curcumin in patients with metabolic syndrome: A randomized, double-blind, placebo-controlled trial. Phytother Res 28(12): 1770-1777.

123. Sheng X, Zhang Y, Gong Z, Huang C, Zang YQ (2008) Improved insulin resistance and lipid metabolism by cinnamon extract through activation of peroxisome proliferator-activated receptors. PPAR Res 2008: 581348 .

124. Aggarwal BB (2010) Targeting inflammation-induced obesity and metabolic diseases by curcumin and other nutraceuticals. Annu Rev Nutr 30:173-199.
125. Ghavipour M, Saedisomeolia A, Djalali M, Sotoudeh G, Eshraghyan MR, et al. (2013) Tomato juice consumption reduces systemic inflammation in overweight and obese females. Br J Nutr 109(11): 2031-2035.

126. Dhara R, Dhar P, Ghosh M (2013) Dietary effects of diacylglycerol rich mustard oil on lipid profile of normocholesterolemic and hypercholesterolemic rats. J Food Sci Technol 50(4): 678-686.

127. Assunção ML, Ferreira HS, dos Santos AF, Cabral CR Jr, Florêncio TM (2009) Effects of dietary coconut oil on the biochemical and anthropometric profiles of women presenting abdominal obesity. Lipids 44(7): 593-601.

128. Pérez-Martínez P, García-Ríos A, Delgado-Lista J, Pérez-Jiménez F, López-Miranda J (2011) Mediterranean diet rich in olive oil and obesity, metabolic syndrome and diabetes mellitus. Curr Pharm Des 17(8): 769-777.

129. Tung YT, Hsu YJ, Chien YW, Huang CC, Huang WC, et al. (2019) Tea seed oil prevents obesity, reduces physical fatigue, and improves exercise performance in high-fat-diet-induced obese ovariectomized mice. Molecules 24(5): 980.

130. Rashed AA, Nawi MNM, Sulaiman K (2017) Assessment of essential oil as a potential anti-obesity agent: A narrative review. J Essential Oil Research 29(1): 1-10.

131. Maruyama C, Kikuchi N, Masuya Y, Hirota S, Araki R, et al. (2013) Effects of green-leafy vegetable intake on postprandial glycemic and lipidemic responses and $\alpha$-tocopherol concentration in normal weight and obese men. J Nutr Sci Vitaminol (Tokyo) 59(4): 264-271.

132. Makris A, Foster GD (2011) Dietary approaches to the treatment of obesity. Psychiatr Clin North Am 34(4): 813-827.

133. Choi BK, Park SB, Lee DR, Lee HJ, Jin YY, et al. (2016) Green coffee bean extract improves obesity by decreasing body fat in high-fat dietinduced obese mice. Asian Pacific Journal of Tropical Medicine 9(7): 635-643.

134. Hasani-Ranjbar S, Nayebi N, Larijani B, Abdollahi M (2009) A systematic review of the efficacy and safety of herbal medicines used in the treatment of obesity. World J Gastroenterol 15(25): 3073-3085.

135. Ruhee RT, Suzuki K (2018) Dietary fiber and its effect on obesity: A review article. Advances in Medical Research 1(1).

136. Chang HC, Huang CN, Yeh DM, Wang SJ, Peng CH, et al. (2013) Oat prevents obesity and abdominal fat distribution, and improves liver function in humans. Plant Foods Hum Nutr 68(1): 18-23.

137. Devalaraja S, Jain S, Yadav H (2011) Exotic fruits as therapeutic complements for diabetes, obesity and metabolic syndrome. Food Res Int 44(7): 1856-1865.

138. Venables MC, Hulston CJ, Cox HR, Jeukendrup AE (2008) Green tea extract ingestion, fat oxidation, and glucose tolerance in healthy humans. Am J Clin Nutr 87(3): 778-784.

139. Rayalam S, Della-Fera MA, Baile CA (2011) Synergism between resveratrol and other phytochemicals: Implications for obesity and osteoporosis. Mol Nutr Food Res 55(8): 1-9.

140. Katiyar SK, Afaq F, Azizuddin K, Mukhtar H (2001) Inhibition of UVB-induced oxidative stress-mediated phosphorylation of mitogenactivated protein kinase signaling pathways in cultured human epidermal keratinocytes by green tea polyphenol epigallocatechin-3gallate. Toxicol Appl Pharmacol 176(2): 110-117.

141. Manna SK, Mukhopadhyay A, Aggarwal BB (2000) Resveratrol suppresses TNF-induced activation of nuclear transcription factors NF-kB, activator protein-1, and apoptosis: Potential role of reactive oxygen intermediates and lipid peroxidation. J Immunol 164(12): 6509-6519.

142. Yu R, Hebbar V, Kim DW, Mandlekar S, Pezzuto JM, et al. (2001) Resveratrol inhibits phorbol ester and UV-induced activator protein 
1 activation by interfering with mitogen-activated protein kinase pathways. Mol Pharmacol 60(1): 217-224.

143. Loo G (2003) Redox-sensitive mechanisms of phytochemical-mediated inhibition of cancer cell proliferation. J Nutr Biochem 14(2): 64-73.

144. Zhang YJ , Gan RY, Li S , Zhou Y, Li AN, et al. (2015) Antioxidant phytochemicals for the prevention and treatment of chronic diseases. Molecules 20(12): 21138-21156.

145. Nordberg J, Arner E SJ (2001) Reactive oxygen species, antioxidants, and the mammalian thioredoxin system. Free Radical Biology \& Medicine 31(11): 1287-1312.

146. Forni C, Facchiano F, Bartoli M, Pieretti S, Facchiano A, et al. (2019) Beneficial role of phytochemicals on oxidative stress and age-related diseases. Biomed Research International 2019: 8748253.

147. Murakami A, Ohnishi K (2012) Target molecules of food phytochemicals: Food science bound for the next dimension 3(5): 462-476.

148. Das L, Vinayak M (2015) Long term effect of curcumin in restoration of tumor suppressor $\mathrm{p} 53$ and phase-II antioxidant enzymes via activation of Nrf2 signaling and modulation of inflammation in prevention of cancer. PLoS One 10(4): e0124000.

149. Chen B, Zhang Y, Wang Y, Rao J, Jiang X, et al. (2014) Curcumin inhibits proliferation of breast cancer cells through Nrf2-mediated downregulation of Fen1 expression. J Steroid Biochem Mol Biol 143: 11-18.

150. Mukherjee A, Sarkar R, Mukherjee S, Biswas J, Roy M (2016) Curcumin boosts up the efficacy of Imatinib Mesylate in chronic myelogenic leukemia cell line K-562 by modulation of various markers. Int J Curr Micobl Ap Sci 5(12): 240-255.

151. Mukherjee A, Mukherjee S, Biswas J, Roy M (2017) Imatinib mesylate resistance in chronic myelogenous leukemia cells may be overcome by Indian spice curcumin. International Journal of Medical Science and Innovative Research 2(6): 535-543.

152. Lee J, Jung E, KohJ , Kim YS, Park D (2008) Efect of rosmarinic acid on atopic dermatitis. The Journal of Dermatology 35(12): 768-771.

153. Lee MT, Lin WC, Yu B, Lee TT (2017) Antioxidant capacity of phytochemicals and their potential effects on oxidative status in animals -A review. Asian-Australas J Anim Sci 30: 299-308.
154. Lee TT, Ciou JY, Chen CL, Yu B (2013) Effect of Echinacea purpurea L. on oxidative status and meat quality in Arbor Acres broilers. J Sci Food Agric 93(1): 166-172.

155. Huang X, Liu G, Guo J, Su Z (2018) The PI3K/AKT pathway in obesity and type 2 diabetes. International Journal of Biological Sciences 14(11): 1483-1496.

156. Suvarna V, Murahari M, Khan T, Chaubey P, Sangave P (2017) Phytochemicals and PI3K inhibitors in cancer-an insight. Front Pharmacol 8: 916.

157. Rodrigues BA, Muñoz VR, Kuga GK, Gaspar RC, Nakandakari S, et al. (2017) Obesity increases mitogen-activated protein kinase phosphatase-3 levels in the hypothalamus of mice. Frontiers in Cellular Neuroscience11:313.

158. Donohoe F, Wilkinson M, Baxter E, Brennan DJ (2020) MitogenActivated Protein Kinase (MAPK) and obesity-related cancer. International Journal of Molecular Sciences 21(4): 1241.

159. Braicu C, Buse M, Busuioc C, Drula R, Gulei D, et al. (2019) A comprehensive review on MAPK: A promising therapeutic target in cancer. Cancers 11(10): 1618.

160. Min S, Yang H, Seo S, Shin S, Chung MY, et al. (2013) Cocoa polyphenols suppress adipogenesis in vitro and obesity in vivo by targeting insulin receptor. Int J Obes 37(4): 584-592.

161. Jung SK, Kim JE, Lee SY, Lee MH, Byun S, et al. (2014) The P110 subunit of PI3-K is a therapeutic target of acacetin in skin cancer. Carcinogenesis 35(1): 123-130.

162. Chen XY, Zhou J, Luo LP, Han B, Chen JY, et al. (2015) Black rice anthocyanins suppress metastasis of breast cancer cells by targeting RAS/RAF/MAPK pathway. BioMed Res Intl 414250: 2015.

163. Angulo P, Kaushik G, Subramaniam D, Dandawate P, Neville K, et al. (2017) Natural compounds targeting major cell signaling pathways: a novel paradigm for osteosarcoma therapy. Journal of Hematology \& Oncology 10(1): 10 .

164. Sun L, Zhou W, Zhang H, Guo Q, Yang W, et al. (2019) Modulation of multiple signaling pathways of the plant-derived natural products in cancer. Frontiers in Oncology 9: 1153. 